\title{
Droop Control of Parallel Dual-Mode Inverters Used in Micro Grid
}

\author{
C.X. Wen, Z.Y. Liu, Z.X. Li \\ Power Electronic and Motor Drive Engineering Research Center \\ North China University of Technology \\ Beijing, China
}

\begin{abstract}
Grid-connected and island control of parallel inverters used in micro grid based on a variety of micro-source were introduced in this paper. Micro-grid in the connected mode should be able to operate automatically with the grid frequency and output high quality electricity in PQ control, and in island mode it can realize load power sharing of the parallel DGs in Droop control [1]. Simultaneously, it should also ensure the stability of the load voltage and frequency in island mode with the droop-based controller which can make the micro-grid smoothly switching between the two operation modes. Finally, simulation of two inverters in the connected mode and island mode was introduced in MATLAB / SIMULINK; the simulation results show the effect of droop control and the load-sharing function. The results also indicate the feasibility and correctness of the control strategy.
\end{abstract}

Keywords-micro grid; parallel dual-mode inverters; PQ control; droop control

\section{INTRODUCTION}

With the rapid development of power electronic technology, in order to ensure the reliability and stability of the power output, more and more distributed generation (DG) systems are used in many cases. The large capacity inverters are gradually replaced by parallel system composed of many small inverters which greatly increase the flexibility and reliability of the system.

The power generation systems of large-scale distributed energy which usually connect to connect the grid by inverters compose of micro-grid. Micro-grid is low-voltage electrical distribution networks, heterogeneously composed of distributed generation, storage, load, and management system with the large primary network. Micro-grid can connect to the wide area electric power system through PCC (Point of Common Coupling), and can operate independently.

Mostly, micro-grid works in grid-connected mode. When the main grid has faults or the power quality can't meet the load requirements, micro-grid should transfer seamlessly from grid-connected mode to island mode and should be reconnected after the main grid returns to normal status. In order to eliminate the transient current and voltage rush associated with the micro grid operation mode transitions, seamless switch control is investigated in this paper.

\section{MicRO-GRID STRUCTURE AND CONTROL ANALYSIS}

The micro-grid structure used in this paper is shown [2] in Figure 1. This micro-grid includes two DGs. Every DG connected to the micro-grid AC bus through a static switch. The micro-grid connected to the main grid via a smart switch (SS).

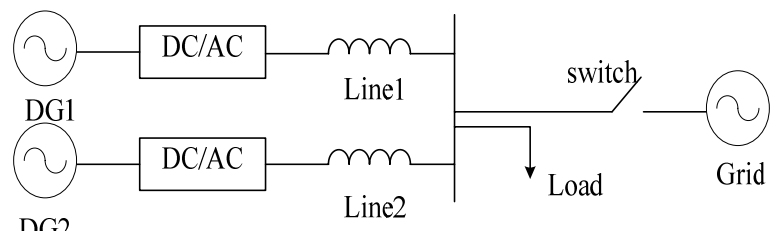

DG2

FIGURE I. MICRO-GRID STRUCTURE DIAGRAM.

\section{A. Single Inverter Grid-Connected PQ Control}

The main purpose of single inverter grid-connected PQ control is to ensure PQ control of distributed power output to maintain active and reactive power in the range of the reference power.

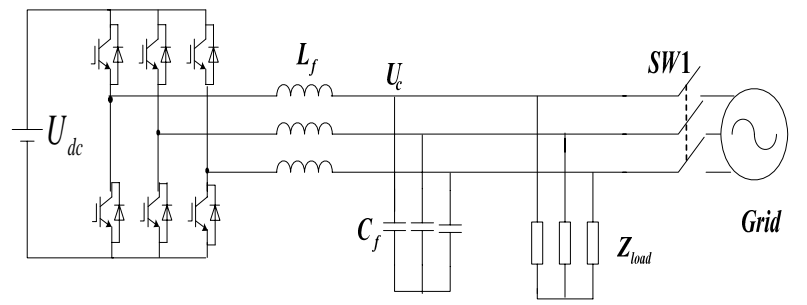

FIGURE II. THE GRID-CONNECTED STRUCTURE DIAGRAM.

Under the DQ coordinate system, the inverter output voltage equation as well as active and reactive power of expression is

$$
\begin{gathered}
P_{r e f}=u_{d} i_{d}+u_{q} i_{q} Q_{r e f}=u_{q} i_{d}-u_{d} i_{q} \\
\left\{\begin{array}{l}
i_{\text {dref }}=\frac{P_{r e f}}{u_{d}} \\
i_{\text {qref }}=-\frac{Q_{\text {ref }}}{u_{d}}
\end{array}\right. \\
\left\{\begin{array}{l}
v_{F d}=\left(k_{d P}+\frac{k_{d I}}{s}\right)\left(i_{d r e f}-i_{d}\right)-\omega L i_{q}+u_{d} \\
v_{F q}=\left(k_{q P}+\frac{k_{q I}}{s}\right)\left(i_{q r e f}-i_{q}\right)+\omega L i_{d}+u_{q}
\end{array}\right.
\end{gathered}
$$




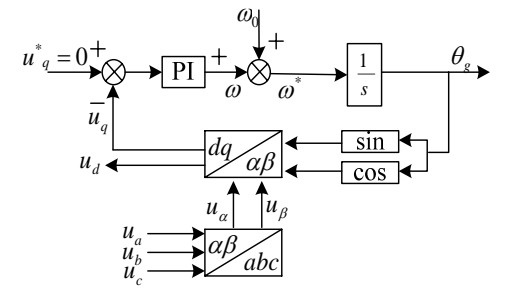

FIGURE III. PRINCIPLE OF SPLL.

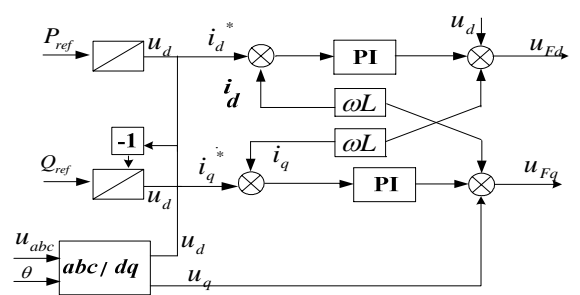

FIGURE IV. DG1 INVERTER PQ CONTROL ON GRID-CONNECTED.

When the micro-grid is in the connected-grid mode, the main inverter operates at a constant current control mode. The reference voltage and frequency are provided and guaranteed by the synchronous rotating coordinate system of d-axis orientation on the grid voltage vector direction, then in the same grid voltage, the inverter output active and reactive power coordinated to its current output respectively Therefore, the inverter output active and reactive power can be controlled to the grid.

\section{B. Droop Control in Island Mode}

According to the analyses above, when the output impendence is inductive, the active power can be controlled by power angle and the reactive power can be controlled by the amplitude of the output voltage. The P-f and Q-V droop control can realize power sharing between parallel inverters. The frequency and the amplitude of the inverter output voltage reference can be expressed as below

$$
\begin{gathered}
f=f^{*}-m\left(P-P^{*}\right) \\
V=V^{*}-n\left(Q-Q^{*}\right)
\end{gathered}
$$

Where $\mathrm{f}^{*}$ and $\mathrm{V}^{*}$ are frequency and amplitude of the output voltage respectively, $\mathrm{P}^{*}$ is the active power reference and $\mathrm{Q}^{*}$ is the reactive power reference. $M$ and $n$ are the droop frequency and amplitude coefficients.

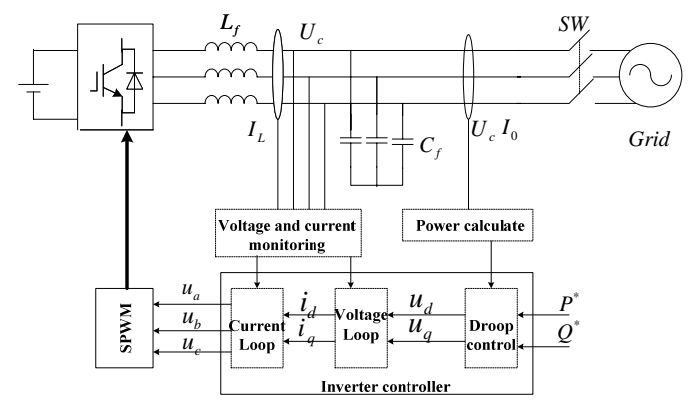

FIGURE V. DROOP CONTROL ON ISLAND MODE.
Droop control measures the value of distributed power output of active and reactive power, and uses the relevant Droop characteristics to determine the frequency and amplitude of the voltage reference value, that is $\mathrm{P} / \mathrm{f}$ and $\mathrm{Q} / \mathrm{V}$ control. The main power control strategy includes outer and inner voltage/current loop to achieve the two components which the inverter output voltage is regulated. By DQ coordinate system, the instantaneous power:

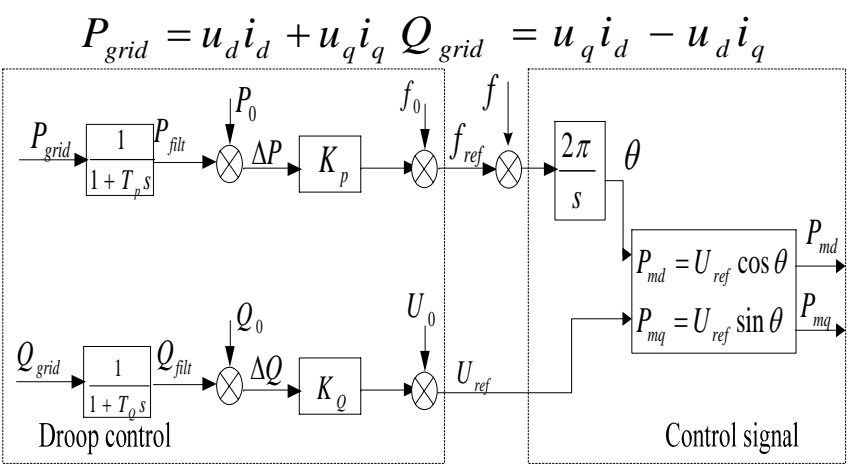

FIGURE VI. DROOP CONTROL SIGNAL FORMING.

\section{SimULATION AND ANALYSIS}

Based on the above analysis, two inverter-based control and off-grid method in which a single inverter adopts PQ control and two inverters adopt net $\mathrm{P} / \mathrm{f} \& \mathrm{Q} / \mathrm{V}$ droop control strategies are proposed in MATLAB/SIMULINK simulation platform [3]. These methods and strategies can efficiently convert the energy and maintain the load stability and balance. Figure 7 illustrates the diagram of the micro-grid test system. Two three-phase inverters are used to research inverters in parallel operation which can eliminate the effect of one inverter suddenly putting into the system or suddenly removing from the system.

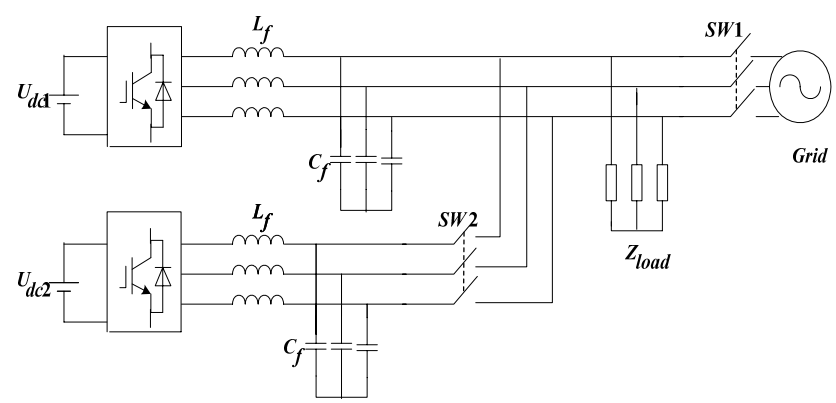

FIGURE VII. SIMULATION OF MICRO-GRID STRUCTURE DIAGRAM.

\section{The Simulation of Dual Mode Inverters}

When the micro-grid is in grid-connected mode, the parameters of each part of the system are shown in TABLE I.

TABLE I. SYSTEM PARAMETERS

\begin{tabular}{|l|l|l|}
\hline Parameter & INVERTER1 & INVERTER2 \\
\hline Input Dc voltage & $800 \mathrm{~V}$ & $800 \mathrm{~V}$ \\
\hline Filter Inductance & $6.76 \mathrm{mH}$ & $3 \mathrm{mH}$ \\
\hline Filter Capacitor & $15 \mathrm{uF}$ & $500 \mathrm{uF}$ \\
\hline DG output power & $2 \mathrm{~kW}$ & $13 \mathrm{~kW}$ \\
\hline SW1,SW2 time & & $0.2 \mathrm{~s}$ \\
\hline
\end{tabular}


TABLE II. SYSTEM PARAMETERS.

\begin{tabular}{|l|c|}
\hline \multicolumn{2}{|c|}{ GRID PARAMETERS } \\
\hline Grid Voltage & $380 \mathrm{~V}$ \\
\hline Grid Frequency & $50 \mathrm{~Hz}$ \\
\hline \multicolumn{2}{|c|}{ LOAD PARAMETERS } \\
\hline Load Voltage & $380 \mathrm{~V}$ \\
\hline Load Frequency & $50 \mathrm{~Hz}$ \\
\hline Active power & $15 \mathrm{~kW}$ \\
\hline
\end{tabular}

Mode 1: Inverter1 operating in the grid-connected mode. Switch1is close and switch 2 is cut off at $t=0.2 \mathrm{~s}$. The voltage of Inverter1 meets the demands of load and main grid. The current of load is supported by inverter1 and main grid, it can make the connected grid and the simulation results are shown in Figure 8 (a. the voltage of Inverter1, b. current of Inverter1).
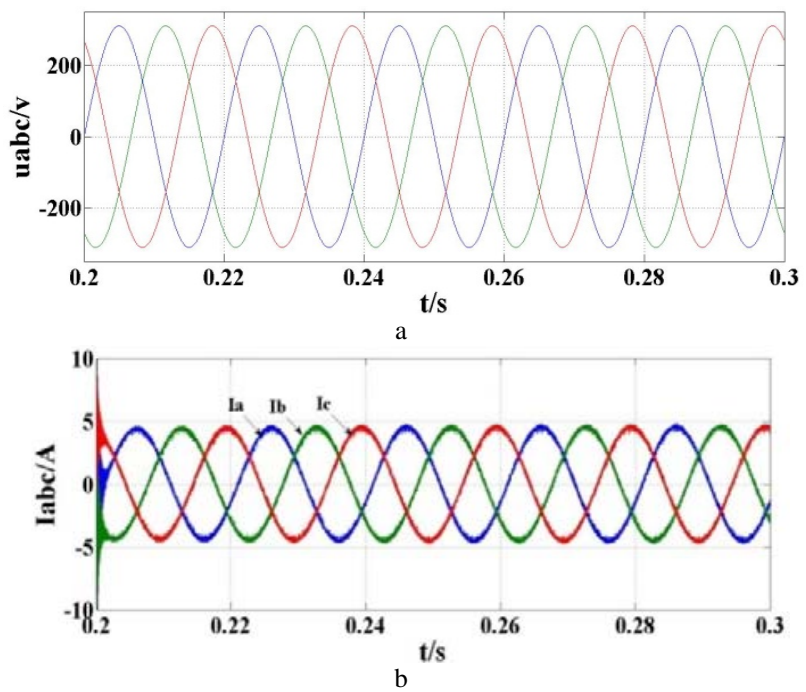

FIGURE VIII. THE SIMULATION OF GRID-CONNECTED MODE.

Mode 2: Inverter2 operating in the island mode. Switch1 is cut off at $\mathrm{t}=0.2 \mathrm{~s}$. The current of load is supported by inverter1 and inverter2; it can meet the demand of load and make it stably operating. The simulation results are shown in Figure 9 (a. the voltage of Inverter 2, b. current of Inverter 2).
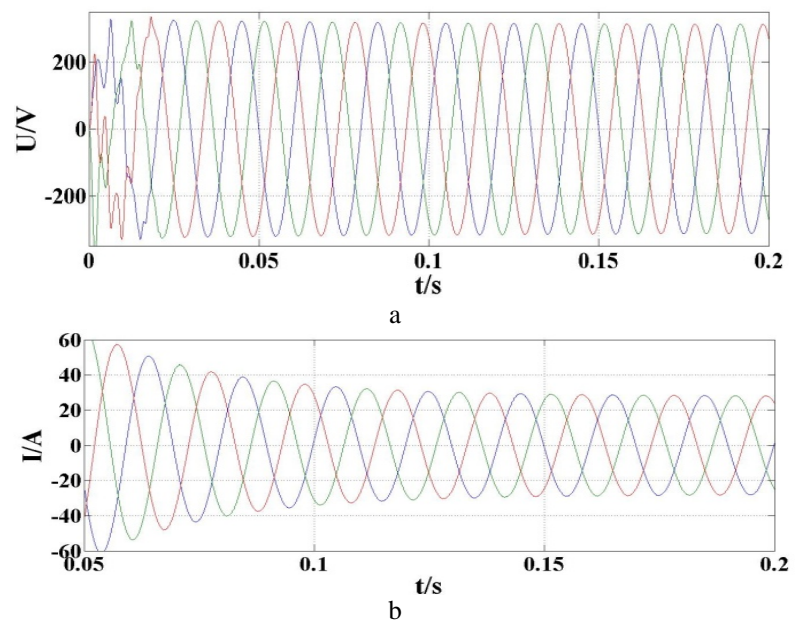

FIGURE IX. THE SIMULATION OF ISLAND MODE. voltage is unchanged from island mode to grid-connected mode and meets the demand of load. Firstly, inverter1 and inverter2 operating in island mode and the current is zero in grid-connected mode before $\mathrm{t}=0.2 \mathrm{~s}$, at $\mathrm{t}=0.2 \mathrm{~s}$, switch 1 is cut in and switch2 is cut off, the grid current can achieve a good transition between two modes [4]. The simulation results are shown in Figure 10 (a. voltage and current of grid, b. current of grid).
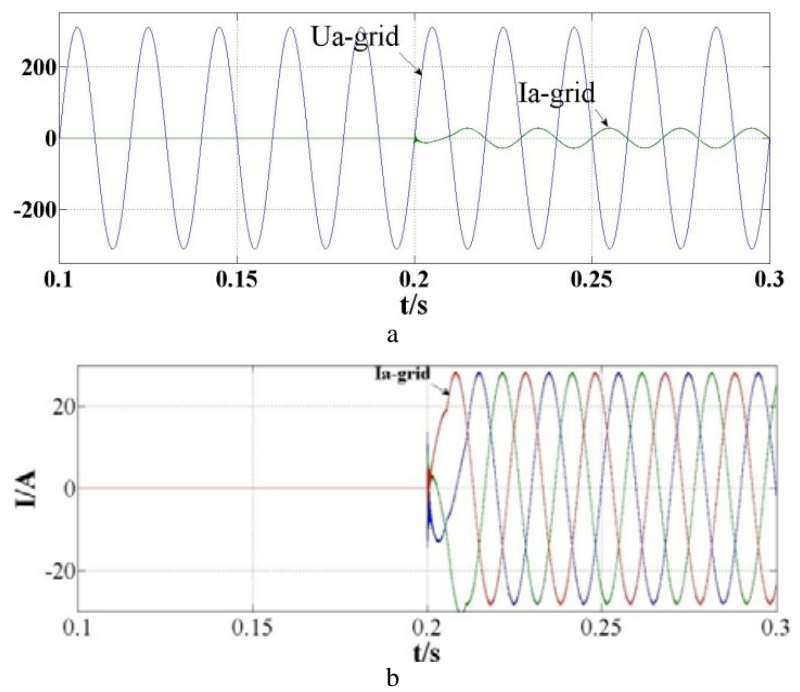

FIGURE X. THE VOLTAGE AND CURRENT FROM ISLAND TO GRID-CONNECTED MODE.

Active power transition from island mode to grid-connected mode: The active power of load is unchanged from island mode to grid-connected mode and meets the demand of load. Firstly, inverter1 and inverter2 operating in island mode and the total active power is $15 \mathrm{~kW}$ before $\mathrm{t}=0.2 \mathrm{~s}$, at $\mathrm{t}=0.2 \mathrm{~s}$, inverter 1 and main grid operating in grid-connected mode, the active power of load can meet demands and operate stably. The simulation results are shown in Figure 11 (a. active power of inverter1, b. active power of inverter2), Figure 12.
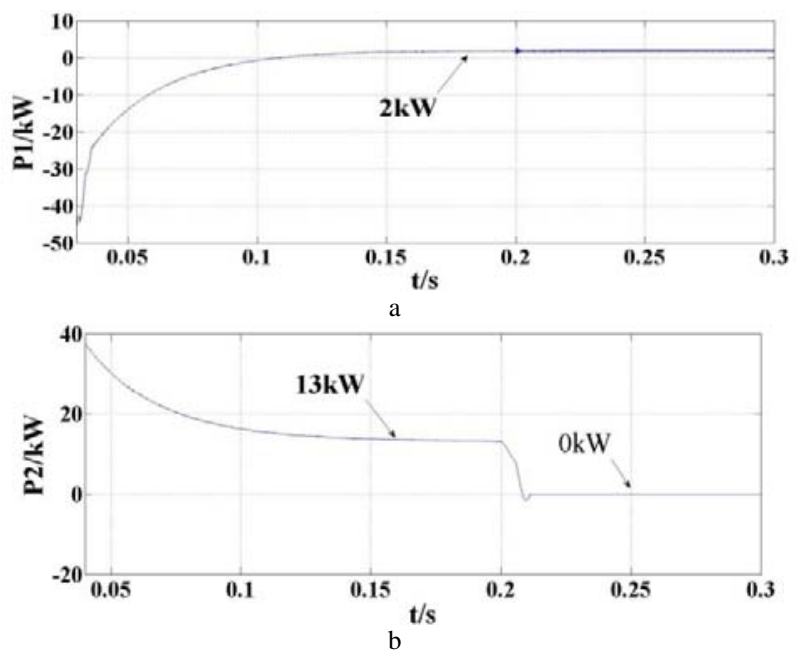

FIGURE XI. INVERTER1 AND INVERTER2 OUTPUT ACTIVE POWER.

Transition from island mode to grid-connected mode: The 


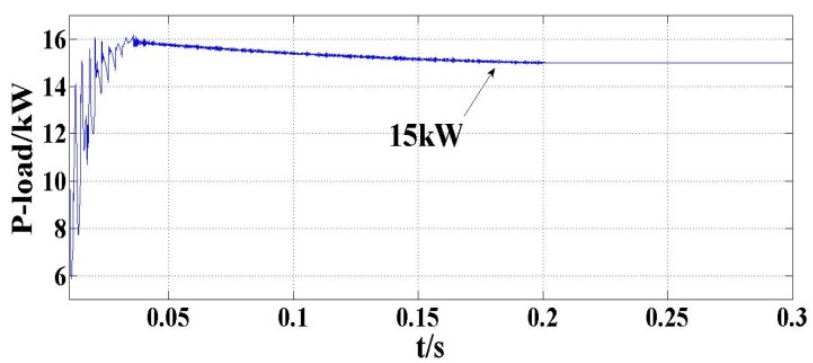

FIGURE XII. ACTIVE POWER ABSORBED BY THE LOAD.

\section{CONCLUSION}

Micro-grid often operates under two typical modes. Micro-grid in the grid-connected mode can make it run automatically with the grid frequency and output high quality electricity. Furthermore, micro-grid in island mode can realize load power sharing of the parallel distributed power of micro-grid. Meanwhile, it can also ensure the stability of the load voltage and frequency. Moreover, the droop controller [5] can make the micro-grid smooth switching between the two kinds of operation modes. Finally, the simulation results indicated that the phase and magnitude of the load voltage are successfully matched to the grid voltage at the point of transfer from island mode to grid-connected operation without any distortions. Similarly, when the mode returns back, the load voltage can quickly approach its desired voltage without voltage and current rush by using the proposed method and strategy.

\section{REFERENCES}

[1] Hu, Shang-Hung., Kuo, Chun-Yi., Lee, Tzung-Lin \& Josep M.Guerrero, "Droop-Controlled Inverters with Seamless Transition between Islanding and Grid-Connected Operations,” ECCE, Phoenix, AZ, Sept 2011, pp.2196-2201.

[2] Yang Zhan gang, Wang Cheng Shan, Che Yan Bo, "A Small-scale Micro-grid System with Flexible Modes of Operation," Automation of Electric Power Systems, vol.33, No.14, July 2009, pp.89-92.

[3] Kanellos,F.D., Tsouchnikas,A.I., \& Hatziargyriou, N.D., "Micro-grid simulation during grid-connected and islanded modes of operation," presented at the Int. Conf. Power Systems Transients (IPST), Montreal, QC, Canada, 2005, Paper IPST05-113.

[4] Chen, C.L. Wang, Y.B. \& Lai, J.S., "Design of parallel inverters for smooth mode transfer micro-grid applications," in Applied Power Electronics Conference and Exposition, 2009 IEEE.APEC 2009, pp. 1288-1294.

[5] Lee, C.T. Jiang, R.P. \& Cheng, P.T., “A grid synchronization method for droop controlled distributed energy resources converters," in Energy Conversion Congress and Exposition, 2011 IEEE. ECCE 2011, pp. 743749. 